\title{
PERSEPSI PELAKU WIRAUSAHA SKALA MIKRO \\ PADA UPAYA PENGEMBANGAN \\ EKOSISTEM PRODUK HALAL DI KOTA TANGERANG
}

\author{
Teuku Fajar Shadiq ${ }^{1}$
}

\section{Abstrak}

Dalam beberapa kurun waktu terakhir ini, eksistensi ekonomi Islam memiliki peran penting dalam ekonomi global (global economy) yaitu dengan bertambahnya populasi penduduk muslim maka meningkat pula konsumsi dan demand produk halal yang sesuai syariah (sharia compliance), yang telah berkembang sub sektor makanan, kosmetik dan obat-obatan (farmasi), jasa keuangan, busana (fashion), travel Muslim yang bertemakan MuslimFriendly Tourism hingga media bertema Islam. Pemicu pertumbuhan tersebut antara lain di dorong oleh pertumbuhan ekonomi (economic growth) dan meningkatkan kepatuhan terhadap nilai-nilai etika. Dari hasil penelitian diketahui rata-rata penilaian responden terhadap variabel sentra bisnis halal adalah sebesar 4.45 dari skala 5 yang mengindikasikan bahwa responden dalam penelitian ini memiliki persepsi yang bagus dari pelaku usaha mikro dalam memenuhi atau mendirikan sentra bisnis halal. Hal ini dapat dilihat dari persepsi responden yang menyatakan bahwa produk yang memiliki sertifikat halal jauh lebih menguntungkan yang mendapatkan nilai 4.65 dari skala 5. Sementara itu, persepsi responden yang menyatakan bahwa sistem bagi hasil lebih menguntungkan dibandingkan sistem bunga mendapatkan penilaian 4.26 dari skala 5. Melihat trend usaha atau bisnis dengan skala seperti ini menggambarkan potensi peningkatan kualitas hidup masyarakat melalui pengembangan usaha produktif sektor riil dengan model industri ultra mikro yang patut di dorong oleh Pemerintah melalu penyediaan landscape yang tertata dengan baik, sehingga mereka memperoleh tempat usaha yang permanen dengan berkontribusi pada pendapat pajak.

Kata Kunci: Wirausaha, Halal, Ekosistem

${ }^{1}$ Universitas Islam Syekh Yusuf Tangerang, email: teuku_fajarshadiq@unis.ac.id 


\section{Abstract}

In recent times, the existence of the Islamic economy has played an important role in the global economy (global economy), namely by increasing the population, the consumption and demand for halal products that are in accordance with sharia (sharia compliance) has also developed, which has developed the food, cosmetics and food sub-sectors. medicine (pharmacy), financial services, clothing (fashion), Muslim travel with the theme of MuslimFriendly Tourism to Islamic-themed media. The triggers for this growth, among others, were driven by economic growth (economic growth) and increased control over ethical values. From the results of the study, it is known that the average respondent's cost to the halal business center variable is 4.45 from a scale of 5 which indicates that the respondent's research has a good perception of micro-entrepreneurs in fulfilling or providing halal business centers. This can be seen from the perception that respondents who stated that having a halal certificate were far more profitable who got a score of 4.65 from a scale of 5. Meanwhile, the perception of respondents who stated that the profit sharing system was more profitable than the 4.26 scoring system of the 5 . system. The trend of businesses illustrates the potential for improving the quality of life of the community through the development of productive sector businesses with an ultra-micro industrial model that should be encouraged by the Government through providing well-ordered landscapes, so that they can obtain a permanent place of business by contributing to tax comments.

Keywords: Enterprises, Halal, Ecosystem

\section{A. PENDAHULUAN}

Dalam beberapa kurun waktu terakhir ini, eksistensi ekonomi Islam memiliki peran penting dalam ekonomi global (global economy) yaitu dengan bertambahnya populasi penduduk muslim maka meningkat pula konsumsi dan demand produk halal yang sesuai syariah (sharia compliance), yang telah berkembang sub sektor makanan, kosmetik dan obat-obatan (farmasi), jasa keuangan, busana (fashion), travel Muslim yang bertemakan Muslim-Friendly Tourism hingga media bertema Islam. Pemicu pertumbuhan tersebut antara lain di dorong 
oleh pertumbuhan ekonomi (economic growth) dan meningkatkan kepatuhan terhadap nilai-nilai etika.

Global Islamic Economy Indicator (GIEI) menempatkan Malaysia menjadi negara yang memiliki ranking tertinggi dalam pertumbuhan sektor produk halal, Indonesia sendiri berhasil mengubah posisi yang awalnya pada ranking 10, namun pada akhir tahun 2018 mecapai ranking ke 5. Sektor makanan memiliki nilai aktivitas bisnis Muslim tertinggi produk halal yang dapat di lihat pada tabel di bawah ini:

Tabel 1. Pengeluaran (Spending) Produk Halal

\begin{tabular}{llccl}
\hline No & $\begin{array}{c}\text { Nilai } \\
\text { Pengeluaran } \\
\text { Produk Halal }\end{array}$ & $\begin{array}{c}\text { Transaksi } \\
\text { (Milyar } \\
\text { Dollar) }\end{array}$ & No & $\begin{array}{c}\text { Ranking Global } \\
\text { Islamic Economic } \\
\text { Indidcator }\end{array}$ \\
\hline 1 & $\begin{array}{l}\text { Makanan dan } \\
\text { Minuman }\end{array}$ & US \$ 1,369 & 1 & Malaysia \\
\hline 2 & Fashion & US \$ 283 & 2 & Uni Emirat Arab \\
\hline 3 & Media & US \$ 220 & 3 & Bahrain \\
\hline 4 & $\begin{array}{l}\text { Travel (Muslim- } \\
\text { Friendly) }\end{array}$ & US \$ 189 & 4 & Saudi Arabia \\
\hline 5 & Farmasi & US \$ 92 & 5 & Indonesia \\
\hline 6 & Kosmetik & US \$ 64 & 6 & Oman \\
\hline
\end{tabular}

Sumber Data: State of the Global Economy Report 2019/20

Kota Tangerang yang berada di Provinsi Banten berbatasan dengan Kabupaten Tangerang di sebelah utara, terletak tepat di sebelah barat Ibu Kota Negara Indonesia, Jakarta. Tangerang merupakan Kota terbesar di Provinsi Banten 164,55 km2 atau sekitar 1,59\% dari luas Provinsi Banten (BPS, 2019), serta ketiga terbesar di kawasan Jabodetabek setelah Jakarta dan Bekasi di provinsi Jawa Barat dan dilalui oleh Jalan Nasional. Tangerang yang kini telah terbagi menjadi Kabupaten Tangerang, Tangerang Selatan Kota Tangerang.

Kota Tangerang sebagai gerbang masuk (Gateway) Ibu Kota Jakarta dimana Pemerintahan Pusat berkedudukan serta keberadaan Bandara Internasional Soekarno-Hatta yang merupakan simbol pintu masuk Indonesia, merupakan potensi strategis dalam pengembangan 
Ekonomi Syariah. Kota Tangerang harus menjadi Brand Ambassador Indonesia sebagai Sharia City (Kota Syariah). Dengan jumlah populasi penduduk sebanyak lebih dari 2.1 juta orang terdiri dari 13 kecamatan (BPS, 2019) memiliki peluang dalam pengembangan Industri Halal, khususnya pada sektor Riil (Makanan, Minuman) termasuk puluhan obyek pariwisata yang menarik bagi wisatawan termasuk dengan cagar-cagar budaya akan menjadi bekal penerimaan Pemkot Tangerang sebagai kota yang memiliki tagline "Akhlaqul Kharimah" , kota Islami. Jika melihat data PDRB berdasarkan BPS 2017 Kota tangerang, sektor Transportasi dan Pergudangan masih menjadi kontributor tertinggi sebesar 31,88\%, kemudian di ikuti industri pengolahan (manufacturing) sebesar 30,26\%, hal ini kemudian yang harus di teliti berapa prosentase aktual IKM nya untuk di intervensi oleh program Pemko, wabil khusus pada IKM yang fokus pada pengembangan industri halal.

Tantangannya kemudian adalah bagaimana mensinergikan potensi-potensi pengembangan ekonomi syariah melalui satu kerangka program kebijakan terintegrasi (Islamization of Economic System) didalam Rencana Pembangunan Daerah serta peran perangkat daerah dan seluruh stakeholders dalam berbagi peran dalam tujuan pengembangan Ekonomi Syariah yang bagian besarnya adalah sektor nyata (riil) tersebut termasuk pengelolaan potensi pendapatan melalui Zakat, Infaq, Shadaqoh dan Waqf untuk menggerakan usaha-usaha produktif yang bersifat Ultra maupun Micro Economy.

Komitmen yang begitu besar dari Walikota Tangerang Arief Wirmansyah B.Cs, M.Kes untuk mendorong maju Kota Tangerang melalui program pemberdayaan masyarakat dibuktikan dengan banyak program participatif yang melibatkan peran masyarakat seperti Kampung Tematik, Kampung Pancasila dan lain sebagainya dengan melibatkan banyak unsur dalam tatanan masyarakat hingga pelibatan Akademisi dalam memfasilitasi dan pendampingan program-program tersebut. Melalui harapan agar anggaran yang telah di distribusikan menjadi nilai manfaat maksimal dalam menjawab kebutuhan masyarakatnya.

Pada akhirnya izinkan Penulis memberikan sumbang saran dalam perspektif ekonomi syariah, bahwasannya untuk mendukung program-program kemasyarakatan yang telah eksisting dalam program Pemko dapat beriringan dengan Master Plan Ekonomi

PERSEPSI PELAKU WIRAUSAHA SKALA MIKRO

128 PADA UPAYA PENGEMBANGAN

EKOSISTEM PRODUK HALAL DI KOTA TANGERANG

Teuku Fajar Shadiq 
Syariah yaitu dengan merencanakan pula berbagai program kegiatan baik soft component maupun fisik dalam agenda kerjanya.

Pemerintah Kota penting untuk mendorong peran serta para counterpart seperti Akademisi, lembaga sosial masyarakat dalam upaya penegambangan Ekonomi Syariah di Kota Tangerang. Sudut pandang akademik memandang penting di bangun pusat kajian dengan pelibatan multi stakeholders untuk merancang percepatan pengembangan dan mengidentifikasi program sejak dari hulu (upstream) hingga hilir (downstream).

Strategi selanjutnya adalah Pemko Tangerang melaksanakan Zonasi kawasan di level kelurahan/kecamatan untuk pelaku UKM dan IKM, dalam jangka panjang pentingnya regulasi investasi dalam mengawal pengembangan produk Halal, mengatur tata cara investasi infrastruktur bagi pelaku usaha yang sesuai persyaratan halal dan perwilayahan industri sehingga dapat meningkatkan daya saing kawasan dan pertumbuhan industri halal yang berpeluang untuk menangkap pangsa pasar dalam negeri dan pasar ekspor dunia.

Membangun Infrastruktur (District Halal) terintegrasi antara pabrik laboratorium, pusat pelatihan \& MUI Centre, kawasan produksi (post-harvest equipments) hasil pertanian, maritim, farmasi, makanan dan minuman, pelayanan (logistik, perbankan, warehouse dan packaging) dan sarana pendukung seperti one stop service centre, convenience store chain, e-commerce sehingga memunculkan satu kawasan "Tangerang Halal Industrial District Hub".

Spektrum persoalan pemerintah dalam upaya pemerataan juga dipengaruhi akibat terkonsentrasinya pembangunan focus pada wilayah yang terklasifikasikan maju dan berkembang dan cenderung meninggalkan wilayah yang seyogianya menjadi lokus prioritas pembangunan nasional. Prioritas pembangunan utamanya adalah meningkatkan kapasitas kemampuan masyarakat yang terkonsentrasi di wilayah pedesaan tempat dimana Tuhan telah menitipkan alokasi sumber daya untuk mencukupi kebutuhan sebagian besar rakyat mengingat dua pertiganya adalah berupa lautan dan sepertiganya adalah daratan bekal untuk mewujudkan masyarakat yang adil makmur dan sejahtera. Kekayaan sumber daya maritim dan pertanian serta didukung dengan berbagai sumber daya air dan mineral semestinya mampu untuk dijadikan keuntungan komparasi 
(comparative advantage) guna mewujudkan bangsa yang tidak hanya berlaku sebagai pasar namun utamanya sebagai pabrik (penghasil) aneka barang dan jasa yang besar di dunia.

Dari berbagai teori disampaikan bahwa sesungguhnya esensi pembangunan merupakan proses multidimensi yang melibatkan perubahan-perubahan pada struktur sosial, sikap mental dan kelembagaan, termasuk pula percepatan atau akselerasi pertumbuhan ekonomi, pengurangan ketimpangan, dan pemberantasan kemiskinan seperti yang disampaikan Todaro (2000) dalam Damarjati (2010), disamping tujuan lain pembangunan adalah untuk memastikan meningkatnya pertumbuhan ekonomi melalui pengembangan sumber daya manusia berkualitas yang mampu mengelola sumber daya alam secara kreatif dan inovatif, mampu dalam mengoptimalisasi faktorfaktor produksi hingga menghasilkan kegiatan ekonomi yang lebih besar dan diharapkan dapat memberikan efek terhadap kegiatan ekonomi di bawahnya yang memiliki lingkup yang lebih kecil (trickle down effect), bukan sebaliknya ketidakmampuan daerah-daerah yang tertinggal untuk berkembang dengan cepat (backwash effect) akibat eksplotasi sumberdaya secara berlebihan dari satu wilayah yang memiliki potensi sebagai pemasok dalam pemenuhan kebutuhan bahan makanan pokok serta tempat produksi komoditi ekspor (hinterland) seperti yang diungkap oleh seorang ekonom yang berasal dari Swedia bernama Myrdal pada tahun 1957 dalam bukunya international-trade theory.

Penelitian ini juga untuk menjawab pandangan seorang ekonom barat yang mengatakan Banyak ekonom masa kini untuk mengesampingkan pertimbangan etika dari lingkup ekonomi dengan alasan bahwa "Judgement-Values" seperti itu didasarkan pada perasaan dan karena itu tidak rasional seperti yang di katakan oleh John Dewey dalam econimist in search of values (1982).

Penelitian ini merupakan sebuah studi empirik untuk menganalisis bagaimana persepsi pelaku Wirausaha Skala Mikro pada upaya pengembangan Ekosistem Produk Halal di Kota Tangerang.

\section{B. KAJIAN TEORITIS}

\section{Moral \& Ethics}

Dalam perspektif Islam Moral dan Etika adalah fundamental sebagai sosok Muslim, sesuai dengan sabda Rasulullah Shalallahu Alaihi 
Wassalam: "Sesungguhnya Aku diutus ke dunia yang paling utama adalah untuk menyempurnakan akhlak" (H.R. Bukhari). Beberapa teori tentang moral dan etika seperti yang dikatakan Cotham (1998:5) mendefinisikannya sebagai pelajaran psikologi dari nilai moral. Secara spesifik, dia mendefinisikan etika dalam konteks bisnis sebagai "the study of what constitutes right and wrong, or good and bad human conduct in a business context".

Moral atau moralitas sering dipakai untuk perbuatan yang sedang dinilai, sedangkan etika di pakai untuk pengkajian sistem nilainilai yang ada. Sedangkan menurut kamus bahasa indonesia, etik berarti nilai mengenai benar salah yang dianut suatu masyarakat, dan etika berarti ilmu yang berkenaan tentang yang baik dan yang buruk serta tentang hak dan kewajiban moral.

Ibn Taimiyah sebagaimana dikutif oleh Adiwarman Azwar Karim menjelaskan bahwa istilah harga yang adil menurut IbnTaimiyah adalah kompensasi yang setara ('iwad\} al-misl) dan harga yang setara (aman al-misl). Dengan demikian harga yang setara adalah harga standar yang berlaku ketika masyarakat menjual barang-barang dagangannya dan secara umum dapat diterima sebagai sesuatu yang setara bagi barangbarang tersebut atau barang-barang yang serupa pada waktu dan tempat khusus. Lepine dan Wesson (2011) "ethics reflects the the degree to which the behaviors of an authority are in accordance with generally accepted moral norms". Dalam hal ini etika merefleksikan perilaku dari individu seseorang sesuai dengan moral dan standar norma yang berlaku. Pada dasarnya seseorang bertanggungjawan atas perilaku sosial di masyarakat yang seharusnya dilandasi oleh moral yang berlaku di masyarakat. Jadi selalu ada kendali moral terhadap setiap perilaku dan sikap seseorang di lingkungan sosial.

Dalam organisasi, etika dan moral tidak bisa dilepaskan, seperti dikatakan oleh John W Newstrom (2007), "ethic is the use of moral principles an values to affect the behavior of individuals and organizations with regard to choice between what is right and wrong" Jadi pernyataan tersebut mengandung makna bahwa perilaku individu dalam organisasi mengutamakan prinsip moral yang berkaitan dengan etika dalam melaksanakan pekerjaan.

Robert Kreitner dan Angelo Kinicki (2010) bahwa: "Ethics involves the study of moral issues and choices. It is concerned with right versus wrong, 
good versus bad, and the many shades of gray supposedly black-and white issues. Moral implication spring from virtually every decussion, both on and of the job".

\section{Rantai Nilai (Value Chain)}

Value chain merupakan suatu konsep yang diperkenalkan Porter tahun 1985, yang menyatakan sebagai serangkaian aktivitas yang dapat memberikan nilai tambah pada produk suatu perusahaan, dimana nilai tambah total yang dari serangkaian aktivitas penambahan nilai tersebut akan menentukan posisi perusahaan tersebut dibandingkan dengan perusahaan lain, atau dengan kata lain competitive advantage dari perusahaan tersebut. Competitive advantage tidak dapat diketahui dari perusahaan secara keseluruhan, namun dibentuk dari aktivitasaktivitas mulai dari perancangan, produksi, pemasaran, pengiriman produk serta aktivitas-aktivitas pendukung lainnya Seluruh aktivitas ini akan menentukan posisi cost perusahaan relatif terhadap perusahaan lain dan bisa menjadi dasar diferensiasi. Kegiatan ini mencakup berbagai macam aktivitas yang dibutuhkan untuk menghadirkan produk dan disposisi akhir setelah pengiriman ke pengguna akhir (Kaplinsky, 2000, P. 206). Menganalisis rantai nilai perusahaan dapat menunjukkan aktivitas terpisah yang membentuk operasi perusahaan (Pearce \& Robinson, 2000).

Gambar 1. Konsepsi Rantai Nilai

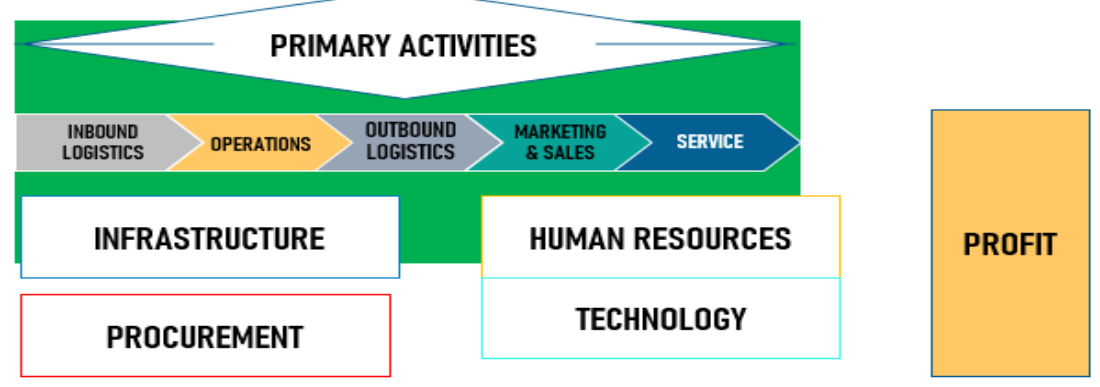

SUPPORT ACTIVITIES

\section{Sentra Bisnis}

Chavan dan Birajdar (2009); Nidheesh (2009); Sujatha (2011) mengatakan kelompok masyarakat berkontribusi secara signifikan 
terhadap pengentasan kemiskinan, transformasi sosial dan pemberdayaan.

Menurut Johnson dan Johnson dalam Sarwono (2005:4-5) menyatakn bahwa kelompok masyarakat adalah kumpulan beberapa kepala keluarga yang menghimpun diri dalam suatu kelompok karena memiliki keserasian dalam tujuan, motif, dan minat yang sama, selanjutnya mendefinisikan kelompok sebagai dua individu atau lebih yang berinteraksi melalui tatap muka (face to face interaction), dan masing-masing menyadari keanggotaannya dalam kelompok, masingmasing menyadari keberadaan anggota kelompok lainnya, masingmasing menyadari saling ketergantungan secara positif dalam mencapai tujuan bersama.

Menurut Trimo (2006) kelompok tani adalah petani yang dibentuk atas dasar kesamaan kepentingan kesamaan kondisi lingkungan (sosial, ekonomi, sumberdaya) keakraban dan keserasian yang dipimpin oleh seorang ketua. Dercon et al (2006) mengatakan akses ke layanan keuangan formal dapat meningkatkan kemampuan rumah tangga untuk mengakumulasi aset dan meningkatkan kegiatan yang menghasilkan pendapatan serta meningkatkan kemampuan mereka untuk secara memadai menghadapi risiko

Walgito, (2008:13-15) menyatakan bahwa kita mendapati bermacam-macam kelompok di masyarakat. Artinya, ada faktor-faktor lain yang mendorong terjadinya kelompok. Alasan atau motivasi seseorang masuk dalam kelompok dapat bervariasi, antara lain: pertama, seseorang masuk dalam kelompok pada umumnya ingin mencapai tujuan yang secara individu tidak dapat atau sulit dicapai. kedua, kelompok dapat memberikan kebutuhan fisiologis maupun kebutuhan psikologis, ketiga, kelompok dapat mendorong pengembangan konsep diri dan mengembangkan harga diri seseorang, keempat, kelompok dapat pula memberikan pengetahuan dan informasi, dan yang terakhir adalah kelompok dapat memberikan keuntungan ekonomis.

Menurut Dev, Kanbur, Galab, \& Alivelu (2012) mengatakan bukti menunjukkan bahwa kegagalan untuk menghubungkan antara kelompok mandiri (Self Help-Groups) dengan sumber daya ekonomi telah merusak keberlanjutan mereka, selanjutnya Sinha (2008) menghubungkan kelompok mandiri ke bank secara signifikan akan 
meningkatkan akses ke layanan keuangan, membantu mengurangi kemiskinan dan memajukan pemberdayaan perempuan.

\section{DESAIN PENELITIAN}

Dari aspek eksplanasi ilmu, penelitian yang akan dilaksanakan ini merupakan desain penelitian analisis statistik deskriptif untuk menjelaskan persepsi responden terhadap pernyataan-pernyataan yang diajukan (Ferdinand, 2006). Adapun populasi dalam penelitian ini adalah pelaku Sentra Bisnis yang berada pada beberapa wilayah Kota Tangerang. Populasi adalah wilayah generalisasi yang mempunyai kualitas dan karakteristik dan ciri-ciri tertentu yang diterapkan sebelumnya (Cooper \& Emory: 1996). Teknik Pengambilan Sampel menggunakan Purposive sampling adalah teknik pengambilan sampel dengan menentukan kriteria-kriteria tertentu, dengan kriteria yang ditetapkan adalah merupakan usaha mikro dan memiliki telepon selular untuk mengisi google forms. Adapun jumlah sampel yang diperoleh adalah sebesar 133 sampel. Penelitian ini dilakukan dengan metode survey melalui Google Forms yang bertujuan untuk mengumpulkan informasi dari responden menggunakan kuesioner berisi daftar pernyataan yang disampaikan langsung kepada reponden yaitu para pelaku usaha Sentra Bisnis di wilayah Kota Tangerang. Data diperoleh melalui database UMKM yang berasal dari Dinas Perdagangan dan Koperasi Kota Tangerang. Kuesioner dalam penelitian ini menggunakan format kuesioner dengan pernyataan tertutup.

\section{ANALISIS DAN PEMBAHASAN}

\section{Responden Berdasarkan Bidang/Kegiatan Usaha}

Tabel 2. Responden Berdasarkan Bidang/Kegiatan Usaha

\begin{tabular}{llr|r|r|r}
\hline & Frequency & Percent & $\begin{array}{c}\text { Valid } \\
\text { Percent }\end{array}$ & \multicolumn{1}{c}{$\begin{array}{c}\text { Cumulative } \\
\text { Percent }\end{array}$} \\
\hline Valid & Toko Kelontong & 6 & 5.3 & 5.3 & 5.3 \\
\cline { 2 - 6 } & $\begin{array}{l}\text { Kuliner } \\
\text { (Makanan/Minuman) }\end{array}$ & 87 & 77.0 & 77.0 & 82.3 \\
\hline $\begin{array}{l}\text { Fashion (Toko } \\
\text { Pakaian/Busana) }\end{array}$ & 9 & 8.0 & 8.0 & 90.3 \\
\hline & & & & 93.8 \\
\hline
\end{tabular}




\begin{tabular}{|c|c|c|c|c|}
\hline $\begin{array}{l}\text { Agrobisnis (Tanaman } \\
\text { Pangan, Sayuran, \& } \\
\text { Buah- } \\
\text { buahan/Tanaman } \\
\text { Perkebunan) }\end{array}$ & 4 & 3.5 & 3.5 & 97.3 \\
\hline $\begin{array}{l}\text { Perikanan } \\
\text { (Budidaya) }\end{array}$ & 3 & 2.7 & 2.7 & 100.0 \\
\hline Total & 113 & 100.0 & 100.0 & \\
\hline
\end{tabular}

Sumber: Data Primer diolah

Berdasarkan Tabel 2 diatas dapat dilihat bahwa bidang/kegiatan usaha yang dominan adalah Kuliner dengan total responden sebanyak 87 orang atau $77 \%$, kemudian diikuti oleh bidang/kegiatan fashion sebanyak 9 orang atau $8 \%$, sementara itu bidang Toko Kelontong sebanyak 6 orang atau 5,3\%, adapun sisanya adalah bidang lainnya seperti Konveksi dan Agrobisnis masing-masing sebanyak 4 orang atau $3,5 \%$, dan perikanan budidaya sebanyak 3 orang atau $2,7 \%$.

\section{Responden Berdasarkan Lokasi Usaha}

Tabel 3. Responden Berdasarkan Lokasi Usaha

\begin{tabular}{|c|c|c|c|c|c|}
\hline & & Frequency & Percent & $\begin{array}{l}\text { Valid } \\
\text { Percent }\end{array}$ & $\begin{array}{c}\text { Cumulative } \\
\text { Percent }\end{array}$ \\
\hline \multirow[t]{10}{*}{ Valid } & Bangunan Sensus & 26 & 23.0 & 23.0 & 23.0 \\
\hline & Khusus Usaha & & & & \\
\hline & Tempat Tinggal & 23 & 20.4 & 20.4 & 43.4 \\
\hline & Rumah Tangga & & & & \\
\hline & Tidak di Bangunan & 49 & 43.4 & 43.4 & 86.7 \\
\hline & dan Lokasi Tetap & & & & \\
\hline & (Pasar Malam, Pasar & & & & \\
\hline & Kaget, dll) & & & & \\
\hline & Keliling & 15 & 13.3 & 13.3 & 100.0 \\
\hline & Total & 113 & 100.0 & 100.0 & \\
\hline
\end{tabular}

Sumber: Data Primer diolah

Berdasarkan Tabel 3 diatas dapat dilihat bahwa lokasi bangunan yang umum pada responden adalah Tidak di bangunan dan Lokasi tetap seperti Pasar Malam, Pasar Kaget, dan lain-lain dengan responden sebanyak 49 orang atau $43,4 \%$, sementara itu usaha yang 
berlokasi pada bangunan khusus usaha sebanyak 26 responden atau $23 \%$, dan responden yang menjadikan tempat tinggalnya menjadi tempat usaha sebanyak 23 responden atau 20,4\%. Adapun usaha yang merupakan pedagangan keliling ada sebanyak 15 orang atau $13,3 \%$. Dapat dilihat bahwa sebagian besar responden merupakan usaha informal mengingat sedikitnya jumlah usaha yang berusaha ditempat usaha.

\section{Responden Berdasarkan Status Tempat Usaha}

Tabel 4. Responden Berdasarkan Status Tempat Usaha

\begin{tabular}{|c|c|c|c|c|c|}
\hline & & Frequency & Percent & $\begin{array}{l}\text { Valid } \\
\text { Percent }\end{array}$ & $\begin{array}{c}\text { Cumulative } \\
\text { Percent }\end{array}$ \\
\hline \multirow[t]{5}{*}{ Valid } & $\begin{array}{l}\text { Milik Sendiri } \\
\text { Bersertifikat }\end{array}$ & 22 & 19.5 & 19.5 & 19.5 \\
\hline & $\begin{array}{l}\text { Milik Sendiri Tidak } \\
\text { Bersertifikat }\end{array}$ & 17 & 15.0 & 15.0 & 34.5 \\
\hline & Sewa/Kontrak & 47 & 41.6 & 41.6 & 76.1 \\
\hline & $\begin{array}{l}\text { Lainnya } \\
\text { (Menumpang) }\end{array}$ & 27 & 23.9 & 23.9 & 100.0 \\
\hline & Total & 113 & 100.0 & 100.0 & \\
\hline
\end{tabular}

Sumber: Data Primer diolah

Berdasarkan Tabel 4 diatas dapat dilihat bahwa hanya 22 orang responden atau $19,5 \%$ dari responden yang merupakan milik sendiri dan bersertifikat. Sementara itu, sebagian besar tempat usaha responden berstatus sewa/kontrak dengan jumlah responden sebanyak 47 orang atau $41,6 \%$. Lebih lanjut tempat usaha yang menumpang (bebas biaya sewa) jumlahnya mencapai 27 orang atau $23,9 \%$. Disamping itu terdapat 17 tempat usaha atau sekitar 15\% dari responden yang merupakan milik sendiri namun tidak memiliki sertifikat.

\section{Responden Berdasarkan Lamanya Usaha}

Tabel 5. Responden Berdasarkan Lamanya Usaha

\begin{tabular}{lr|r|r|r}
\hline & Frequency & Percent & $\begin{array}{c}\text { Valid } \\
\text { Percent }\end{array}$ & $\begin{array}{c}\text { Cumulative } \\
\text { Percent }\end{array}$ \\
\hline Valid kurang dari 10 tahun & 71 & 62.8 & 62.8 & 62.8 \\
\hline
\end{tabular}




\begin{tabular}{l|r|r|r|r}
\hline 11 tahun s.d 20 tahun & 35 & 31.0 & 31.0 & 93.8 \\
\hline Lebih dari 20 tahun & 7 & 6.2 & 6.2 & 100.0 \\
\hline Total & 113 & 100.0 & 100.0 & \\
\hline
\end{tabular}

Sumber: Data Primer diolah

Berdasarkan Tabel 5 diatas dapat dilihat bahwa sebagian besar usaha yakni sekitar 71 responden atau $62,8 \%$ memiliki umur usaha kurang dari 10 tahun. Disamping itu sekitar 35 responden memiliki umur usaha antara 11 hingga 20 tahun. Terakhir terdapat 7 responden atau $6,2 \%$ usaha yang memiliki umur lusaha lebih dari 20 tahun. Dengan demikian dapat dilihat bahwa usaha yang dilakukan oleh responden umumnya berupa usaha-usaha yang masih relatif baru/rintisan.

\section{Responden Berdasarkan Umur Pemilik Usaha}

Tabel 6. Responden Berdasarkan Umur Pemilik Usaha

\begin{tabular}{llr|r|r|r}
\hline & Frequency & Percent & $\begin{array}{c}\text { Valid } \\
\text { Percent }\end{array}$ & $\begin{array}{c}\text { Cumulative } \\
\text { Percent }\end{array}$ \\
\hline Valid & Kurang dari 25 tahun & 35 & 31.0 & 31.0 & 31.0 \\
\cline { 2 - 6 } & 25 tahun s.d 40 tahun & 40 & 35.4 & 35.4 & 66.4 \\
\cline { 2 - 6 } & 41 tahun s.d 55 tahun & 35 & 31.0 & 31.0 & 97.3 \\
\cline { 2 - 6 } & lebih dari 56 tahun & 3 & 2.7 & 2.7 & 100.0 \\
\cline { 2 - 6 } & Total & 113 & 100.0 & 100.0 & \\
\hline
\end{tabular}

Sumber: Data Primer diolah

Berdasarkan Tabel 6 diatas dapat dilihat bahwa rentang usia pemilik usaha dalam penelitian ini cukup merata antara generasi $\mathrm{Z}$ (usia kurang dari 25 tahun) dengan jumlah responden sebanyak 35 orang atau $31 \%$, generasi $Y$ (usia 25 tahun s.d 40 tahun) dengan jumlah responden sebanyak 40 orang atau 35,4\%, serta generasi $\mathrm{X}$ (usia 41 tahun s.d 55 tahun) dengan jumlah responden sebanyak 35 orang atau $31 \%$. Adapun untuk responden dengan usia lebih dari 56 tahun adalah sebanyak 3 orang atau $2,7 \%$. 
al-Mizan, Vol. 5, No.1, hlm. 125-147, Februari 2021,

P.ISSN : 2085-6792, E.ISSN : 2656-7164

\section{Responden Berdasarkan Pendidikan yang ditamatkan}

Tabel 7. Responden Berdasarkan Pendidikan yang ditamatkan

\begin{tabular}{|c|c|c|c|c|c|}
\hline & & Frequency & Percent & $\begin{array}{l}\text { Valid } \\
\text { Percent }\end{array}$ & $\begin{array}{c}\text { Cumulative } \\
\text { Percent }\end{array}$ \\
\hline \multirow[t]{7}{*}{ Valid } & Tidak Tamat SD & 6 & 5.3 & 5.3 & 5.3 \\
\hline & $\begin{array}{l}\text { Taman SD atau } \\
\text { sederajat }\end{array}$ & 14 & 12.4 & 12.4 & 17.7 \\
\hline & $\begin{array}{l}\text { Tamat SMP atau } \\
\text { sederajat }\end{array}$ & 21 & 18.6 & 18.6 & 36.3 \\
\hline & $\begin{array}{l}\text { Tamat SMA atau } \\
\text { sederajat }\end{array}$ & 57 & 50.4 & 50.4 & 86.7 \\
\hline & Diploma & 6 & 5.3 & 5.3 & 92.0 \\
\hline & Sarjana & 9 & 8.0 & 8.0 & 100.0 \\
\hline & Total & 113 & 100.0 & 100.0 & \\
\hline
\end{tabular}

Sumber: Data Primer diolah

Berdasarkan Tabel 7 diatas dapat dilihat bahwa pendikan mayoritas dari responden adalah SMA atau sederajat sebanyak 57 orang atau $50.4 \%$. Selanjutnya diikuti oleh responden dengan pendidikan SMP sebanyak 21 orang atau sekitar 18,6\% dan dengan pendidikan SD atau sederajat dengan jumlah sebanyak 14 orang atau $12,4 \%$. Sementara itu responden yang menamatkan pendidikan tinggi seperti Diploma dan Sarjana masing-masing sebesar 6 dan 9 orang, atau sekitar 5,3\% dan 8,0\%. Adapun responden yang tidak menamatkan pendidikan SD adalahs ebesar 6 orang atau 5,3\%.

7. Responden Berdasarkan Banyaknya Pekerja termasuk Pemilik

Tabel 8. Responden Berdasarkan Banyaknya Pekerja termasuk Pemilik

\begin{tabular}{lrr|r|r|r}
\hline & Frequency & Percent & $\begin{array}{c}\text { Valid } \\
\text { Percent }\end{array}$ & $\begin{array}{c}\text { Cumulative } \\
\text { Percent }\end{array}$ \\
\hline Valid & 1.00 & 42 & 37.2 & 37.2 & 37.2 \\
\cline { 2 - 6 } & 2.00 & 34 & 30.1 & 30.1 & 67.3 \\
\cline { 2 - 6 } & 3.00 & 21 & 18.6 & 18.6 & 85.8 \\
\hline 4.00 & 5 & 4.4 & 4.4 & 90.3 \\
\hline & 5.00 & 5 & 4.4 & 4.4 & 94.7 \\
\hline
\end{tabular}

PERSEPSI PELAKU WIRAUSAHA SKALA MIKRO

138 PADA UPAYA PENGEMBANGAN

EKOSISTEM PRODUK HALAL DI KOTA TANGERANG

Teuku Fajar Shadiq 


\begin{tabular}{l|r|r|r|r}
\hline 9.00 & 1 & .9 & .9 & 97.3 \\
\hline 10.00 & 2 & 1.8 & 1.8 & 99.1 \\
\hline 20.00 & 1 & .9 & .9 & 100.0 \\
\hline Total & 113 & 100.0 & 100.0 & \\
\hline
\end{tabular}

Sumber: Data Primer diolah

Berdasarkan Tabel 8 diatas dapat dilihat bahwa usaha yang dilakukan oleh responden memiliki jumlah pekerja sebanyak satu, dua, dan tiga orang, dengan jumlah masing-masing sebesar 42 orang, 34 orang, dan 21 orang. Dengan demikian dapat disimpulkan bahwa sebagian besar usaha yang dimiliki responden merupakan usaha mikro berdasarkan jumlah tenaga kerja.

\section{Responden Berdasarkan Perkiraan Omzet per-bulan}

Tabel 9. Responden Berdasarkan Perkiraan Omzet per-bulan

\begin{tabular}{llr|r|r|r}
\hline & Frequency & Percent & $\begin{array}{c}\text { Valid } \\
\text { Percent }\end{array}$ & $\begin{array}{c}\text { Cumulative } \\
\text { Percent }\end{array}$ \\
\hline Valid & Kurang dari Rp 10 Juta & 68 & 60.2 & 60.2 & 60.2 \\
\cline { 2 - 6 } & Rp 10 Juta s.d Rp 25 Juta & 26 & 23.0 & 23.0 & 83.2 \\
\cline { 2 - 6 } & Rp 26 Juta Keatas & 19 & 16.8 & 16.8 & 100.0 \\
\cline { 2 - 6 } & Total & 113 & 100.0 & 100.0 & \\
\hline
\end{tabular}

Sumber: Data Primer diolah

Berdasarkan Tabel 9 diatas dapat dilihat bahwa mayoritas omzet usaha yang dimiliki responden kurang dari Rp 10 juta per bulan dengan jumlah responden sebanyak 68 orang atau $60,2 \%$. Selanjutnya diikuti oleh responden dengan jumlah omzet usaha antara Rp 10 juta s.d Rp 25 Juta dengan responden sebanyak 26 orang atau 23\%. Adapun responden yang memiliki usaha dengan omzet lebih dari 26 Juta adalah sebanyak 19 orang atau sekitar $16.8 \%$. Melihat profil sebagian besar responden berdasarkan omzet usaha merupakan usaha mikro. 
al-Mizan, Vol. 5, No.1, hlm. 125-147, Februari 2021,

P.ISSN : 2085-6792, E.ISSN : 2656-7164

\section{Responden Berdasarkan Perkiraan Biaya-biaya per-bulan}

Tabel 10. Responden Berdasarkan Perkiraan Biaya-biaya per-bulan

\begin{tabular}{|c|c|c|c|c|c|}
\hline & & Frequency & Percent & $\begin{array}{c}\text { Valid } \\
\text { Percent }\end{array}$ & $\begin{array}{c}\text { Cumulative } \\
\text { Percent }\end{array}$ \\
\hline \multirow[t]{4}{*}{ Valid } & $\begin{array}{l}\text { Kurang dari } \\
\text { Rp } 5 \text { Juta }\end{array}$ & 57 & 50.4 & 50.4 & 50.4 \\
\hline & $\begin{array}{l}\text { Rp } 5 \text { Juta s.d } \\
\text { Rp } 10 \text { Juta }\end{array}$ & 31 & 27.4 & 27.4 & 77.9 \\
\hline & $\begin{array}{l}\text { Rp } 10 \text { Juta } \\
\text { Keatas }\end{array}$ & 25 & 22.1 & 22.1 & 100.0 \\
\hline & Total & 113 & 100.0 & 100.0 & \\
\hline
\end{tabular}

Sumber: Data Primer diolah

Berdasarkan Tabel 10 diatas dapat dilihat bahwa besarnya biayabiaya dengan kategori kurang dari Rp 5 Juta adalah sebanyak 57 orang atau 50,4\%. Sedangakan untuk kategori biaya Rp 5 Juta s.d Rp 10 Juta adalah sebanyak 31 orang atau $27,4 \%$. Sedangkan usaha yang memiliki biaya bulanan lebih dari Rp 10 Juta adalah sebanyak 25 orang atau $22,1 \%$.

\section{Responden Berdasarkan Kepemilikan Pinjaman Usaha Kepada Orang Lain}

Tabel 11. Responden Berdasarkan Kepemilikan Pinjaman Usaha Kepada Orang Lain

\begin{tabular}{llr|r|r|r}
\hline & & Frequency & Percent & $\begin{array}{c}\text { Valid } \\
\text { Percent }\end{array}$ & $\begin{array}{c}\text { Cumulative } \\
\text { Percent }\end{array}$ \\
\hline Valid & Ya & 8 & 7.1 & 7.1 & 7.1 \\
\cline { 2 - 6 } \cline { 6 - 7 } & Tidak & 105 & 92.9 & 92.9 & 100.0 \\
\cline { 2 - 5 } & Total & 113 & 100.0 & 100.0 & \\
\hline
\end{tabular}

Sumber: Data Primer diolah

Berdasarkan Tabel 11 diatas dapat dilihat bahwa hanya 8 orang dari 113 responden yang memiliki pinjaman atau kredit kepada orang lain secara personal, sedangkan sisanya sebanyak 105 orang tidak memiliki pinjaman kepada orang lain. 


\section{Responden Berdasarkan Kepemilikan Pinjaman Usaha di Bank/Koperasi}

Tabel 12. Responden Berdasarkan Kepemilikan Pinjaman Usaha di Bank/Koperasi

\begin{tabular}{llr|r|r|r}
\hline & Frequency & Percent & $\begin{array}{c}\text { Valid } \\
\text { Percent }\end{array}$ & \multicolumn{2}{c}{$\begin{array}{c}\text { Cumulative } \\
\text { Percent }\end{array}$} \\
\hline Valid & Ya & 11 & 9.7 & 9.7 & 9.7 \\
\cline { 2 - 6 } & Tidak & 102 & 90.3 & 90.3 & 100.0 \\
\cline { 2 - 6 } & Total & 113 & 100.0 & 100.0 & \\
\hline
\end{tabular}

Sumber: Data Primer diolah

Berdasarkan Tabel 12 diatas dapat dilihat bahwa hanya 11 orang dari 113 responden yang memiliki pinjaman atau kredit di Bank atau Koperasi, sedangkan sisanya sebanyak 102 orang tidak memiliki pinjaman kepada orang lain. Melihat data kepemilikan pinjaman atau kredit dapat dideskripsikan bahwa usaha-usaha yang masuk dalam sampel penelitian ini belum mengambil kesempatan menggunakan fasilitas kredit/pembiayaan baik melalui pinjaman personal ke orang lain atau ke Lembaga Keuangan.

\section{Persepsi Responden terhadap Primary Activities}

Tabel 13. Persepsi Responden terhadap Primary Activities

\begin{tabular}{c|l|c|c|c|c}
\hline No. & \multicolumn{1}{|c|}{ Indikator } & Min. & Max. & Mean & $\begin{array}{c}\text { Std. } \\
\text { Deviation }\end{array}$ \\
\hline 1 & $\begin{array}{l}\text { Bahan baku yang saya } \\
\text { peroleh harganya murah } \\
\text { dan mudah }\end{array}$ & 1.00 & 5.00 & 4.27 & 1.02 \\
\hline 2 & $\begin{array}{l}\text { Saya mampu } \\
\text { menghasilkan barang } \\
\text { yang bagus dan disukai } \\
\text { pelanggan }\end{array}$ & 3.00 & 5.00 & 4.73 & 0.57 \\
\hline 3 & $\begin{array}{l}\text { Saya bisa menjual } \\
\text { produk dengan mudah } \\
\text { langsung ke pelanggan }\end{array}$ & 2.00 & 5.00 & 4.58 & 0.75 \\
\hline
\end{tabular}




\begin{tabular}{c|l|c|c|c|c}
\hline 4 & $\begin{array}{l}\text { Saya mampu } \\
\text { menjelaskan kelebihan } \\
\text { produk yang saya jual } \\
\text { dengan baik kepada } \\
\text { pelanggan }\end{array}$ & 3.00 & 5.00 & 4.61 & 0.66 \\
\hline 5 & $\begin{array}{l}\text { Jika ada komplain dari } \\
\text { pelanggan, saya segera } \\
\text { memperbaikinya }\end{array}$ & 1.00 & 5.00 & 4.68 & 0.70 \\
\hline & \multicolumn{1}{c}{ Rata-rata } & 2.00 & 5.00 & 4.58 & 0.74 \\
\hline
\end{tabular}

Sumber: Data Primer diolah

Berdasarkan tabel 13 diatas diketahui rata-rata penilaian responden terhadap variabel Primary activities adalah sebesar 4.58 dari skala 5 yang mengindikasikan bahwa responden dalam penelitian ini memiliki persepsi yang sangat bagus terhadap pemenuhan primary activities untuk menjalankan usaha mikro. Hal ini dapat dilihat dari kemampuan pelaku usaha mikro dalam dalam menghasilkan barang yang berkualitas dan disukai oleh pelanggan yang ditunjukkan oleh persepsi responden yang mencapai nilai 4.73 dari skala 5. Sementara itu, dilihat dari pernyataan yang dijawab oleh responden diketahui bahwa pemenuhan pelaku usaha mikro dalam memperoleh bahan baku dengan harga yang murah dan akses yang mudah memiliki nilai yang paling kecil dibandingkan dengan rata-rata pernyataan lain dalam variabel ini dimana nilainya hanya mencapai 4.27 dari skala 5 .

\section{Persepsi Responden terhadap Support Activities}

Tabel 14. Persepsi Responden terhadap Support Activities

\begin{tabular}{c|l|c|c|c|c}
\hline No. & \multicolumn{1}{|c|}{ Indikator } & Min. & Max. & Mean & $\begin{array}{c}\text { Std. } \\
\text { Deviation }\end{array}$ \\
\hline 1 & $\begin{array}{l}\text { Akses lokasi menuju } \\
\text { lokasi penjualan sangat } \\
\text { baik }\end{array}$ & 1.00 & 5.00 & 4.57 & 0.79 \\
\hline $\begin{array}{l}\text { Saya mampu } \\
\text { merencanakan berapa } \\
\text { bahan baku yang } \\
\text { dibutuhkan untuk } \\
\text { memproduksi barang } \\
\text { yang akan dijual }\end{array}$ & 1.00 & 5.00 & 4.53 & 0.79 \\
\hline
\end{tabular}

PERSEPSI PELAKU WIRAUSAHA SKALA MIKRO

142 PADA UPAYA PENGEMBANGAN

EKOSISTEM PRODUK HALAL DI KOTA TANGERANG

Teuku Fajar Shadiq 


\begin{tabular}{l|l|c|c|c|c}
\hline 3 & $\begin{array}{l}\text { Saya mempunyai } \\
\text { kemampuan untuk } \\
\text { membuat produk yang } \\
\text { bagus, dan saya juga } \\
\text { memiliki karyawan yang } \\
\text { mampu membuat } \\
\text { produk yang bagus/ } \\
\text { berkualitas }\end{array}$ & 1.00 & 5.00 & 4.41 & 0.90 \\
\hline 4 & $\begin{array}{l}\text { Alat-alat yang saya } \\
\text { gunakan masih bagus/ } \\
\text { layak pakai dan canggih }\end{array}$ & 1.00 & 5.00 & 4.14 & 1.07 \\
\hline
\end{tabular}

Sumber: Data Primer diolah

Berdasarkan tabel 14 diatas diketahui rata-rata penilaian responden terhadap variabel Support activities adalah sebesar 4.41 dari skala 5 yang mengindikasikan bahwa responden dalam penelitian ini memiliki persepsi yang bagus terhadap pemenuhan support activities untuk menjalankan usaha mikro. Hal ini dapat dilihat dari akses lokasi yang sangat baik dengan ditunjukkan oleh persepsi responden yang mencapai nilai 4.57 dari skala 5. Sementara itu, dilihat dari pernyataan yang dijawab oleh responden diketahui bahwa kecanggihan alat yang digunakan untuk produksi memiliki nilai yang paling kecil dibandingkan dengan rata-rata pernyataan lain dalam variabel ini dimana nilainya hanya mencapai 4.14 dari skala 5 yang mengindikasikan bahwa alat-alat yang digunakan kurang modern.

\section{Persepsi Responden terhadap Moral dan Etika}

Tabel 15. Persepsi Responden terhadap Moral dan Etika

\begin{tabular}{c|l|c|c|c|c}
\hline No. & \multicolumn{1}{|c|}{ Indikator } & Min. & Max. & Mean & $\begin{array}{c}\text { Std. } \\
\text { Deviation }\end{array}$ \\
\hline 1 & $\begin{array}{l}\text { Tidak masalah bagi saya } \\
\text { untuk sesekali } \\
\text { berbohong kepada } \\
\text { pelanggan untuk } \\
\text { mendapatkan } \\
\text { keuntungan }\end{array}$ & 1.00 & 5.00 & 2.17 & 1.73 \\
\hline
\end{tabular}




\begin{tabular}{c|l|c|c|c|c}
\hline 2 & $\begin{array}{l}\text { Saya tidak masalah jika } \\
\text { harus memasok produk } \\
\text { saya kepada usaha } \\
\text { sejenis }\end{array}$ & 1.00 & 5.00 & 3.81 & 1.65 \\
\hline \multicolumn{1}{|c|}{ Rata-rata } & 1.00 & 5.00 & 2.99 & 1.69 \\
\hline
\end{tabular}

Sumber: Data Primer diolah

Berdasarkan tabel 15 Pertanyaan nomor 1 pada variabel ini merupakan pernyataan dalam negatif sehingga penafsirannya dilakuksan secara terbalik. Pada tabel diatas diketahui rata-rata penilaian responden terhadap variabel Moral dan Etika adalah sebesar 2.99 dari skala 5 yang mengindikasikan bahwa responden dalam penelitian ini memiliki persepsi yang cukup bagus dalam memandang. Hal ini dapat dilihat pada pernyataan responden pada poin "tidak masalah bagi saya untuk sesekali berbohong kepada pelanggan untuk mendapatkan keuntungan" yang hanya mendapatkan nilai 2.17 dari skala 5. Sementara itu indikator lainnya dapat dilihat pada pertanyaan "Saya tidak masalah jika harus memasok produk saya kepada usaha sejenis" yang hanya mendapatkan nilai 3.81 dari skala 5 yang mengindikasikan bahwa tidak cukup banyak usaha mikro yang bersedia memasok untuk usaha sejenis.

\section{Persepsi Responden terhadap Sentra Bisnis Halal}

Tabel 16. Persepsi Responden terhadap Sentra Bisnis Halal

\begin{tabular}{c|l|c|c|c|c}
\hline No. & \multicolumn{1}{|c|}{ Indikator } & Min. & Max. & Mean & $\begin{array}{c}\text { Std. } \\
\text { Deviation }\end{array}$ \\
\hline 1 & $\begin{array}{l}\text { Sistem bagi hasil jauh } \\
\text { lebih adil dan } \\
\text { menguntungkan } \\
\text { dibandingkan dengan } \\
\text { menggunakan bunga }\end{array}$ & 1.00 & 5.00 & 4.26 & 1.22 \\
\hline $\begin{array}{l}\text { Produk yang } \\
\text { bersertifikat Halal jauh } \\
\text { lebih menguntungkan } \\
\text { dibandingkan dengan } \\
\text { yang belum tersertfikat } \\
\text { halal }\end{array}$ & 1.00 & 5.00 & 4.65 & 0.83 \\
\hline & \multicolumn{1}{|c|}{ Rata-rata } & 1.00 & 5.00 & 4.45 & 1.03 \\
\hline
\end{tabular}

Sumber: Data Primer diolah 
Berdasarkan tabel 16 diatas diketahui rata-rata penilaian responden terhadap variabel sentra bisnis halal adalah sebesar 4.45 dari skala 5 yang mengindikasikan bahwa responden dalam penelitian ini memiliki persepsi yang bagus dari pelaku usaha mikro dalam memenuhi atau mendirikan sentra bisnis halal. Hal ini dapat dilihat dari persepsi responden yang menyatakan bahwa produk yang memiliki sertifikat halal jauh lebih menguntungkan yang mendapatkan nilai 4.65 dari skala 5. Sementara itu, persepsi responden yang menyatakan bahwa sistem bagi hasil lebih menguntungkan dibandingkan sistem bunga mendapatkan penilaian 4.26 dari skala 5 .

\section{E. KESIMPULAN}

Berdasarkan data yang telah dihimpun diatas diketahui bahwa mayoritas pelaku usaha mikro di Kota Tangerang merupakan usaha dengan bidang kuliner, tidak memiliki lokasi tetap dalam berusaha, berpendidikan SMA keatas, memiliki jumlah pekerja 1 hingga tiga orang, usia usaha kurang dari 10 tahun, dan mayoritas tidak memiliki akses pembiayaan baik ke perorangan maupun ke lembaga keuangan. Berdasarkan perspektif responden terhadap pengembangan sentra bisnis halal diketahui bahwa responden memiliki niat yang cukup kuat untuk terbentuknya sentra bisnis halal sekalipun pada skala ultra mikro, serta menganggap bahwa pembiayaan dengan prinsip bagi hasil jauh lebih menguntungkan daripada prinsip bunga. Responden juga telah memiliki persepsi yang baik terhadap pengamalan moral dalam berusaha. Namun demikian pengembangan usaha ini masih sedikit terhambat pada perolehan bahan baku yang mudah dan murah serta alat-alat produksi yang sederhana. Melihat trend usaha atau bisnis dengan skala seperti ini menggambarkan potensi peningkatan kualitas hidup masyarakat melalui pengembangan usaha produktif sektor riil dengan model industri ultra mikro yang patut di dorong oleh Pemerintah melalu penyediaan landscape yang tertata dengan baik, sehingga mereka memperoleh tempat usaha yang permanen dengan berkontribusi pada pendapat pajak, pemanfaatan produk lokal, serapan tenaga kerja dan ketahanan pangan keluarga. 


\section{DAFTAR PUSTAKA}

Colquitt, Jason A., Jeffery A. LePine, and Michael J. Wesson. (2011). Organizational Behavior. New York: McGraw-Hill.

Cooper dan Emory. (1996). Metode Penelitian Bisnis. Jakarta:Erlangga.

Damarjati (2010), Analisis Faktor-Faktor Yang Mempengaruhi Kesenjangan Pendapatan Di Propinsi Jawa Tengah.

Dipta, I Wayan. (2008). Strategi Penguatan Usaha Mikro, Kecil dan Menengah (UMKM) melalui Kerjasama Kemitraan Pola CSR. INFOKOP, Vol. 16.

Ferdinand, A. (2006). Metode Penelitian Manajemen: Pedoman Penelitian untuk skripsi, Tesis dan Disertai Ilmu Manajemen. Semarang: Universitas Diponegoro.

Gouët, C., \& Van Paassen, A. (2012). "Smallholder Marketing Cooperatives and Smallholders Market Access": Lessons Learned from the Actors Involved. The Journal of Agricultural Education and Extension, 18(4), 369-385.

Hejazziey, Djawahir. (2009) "Pemberdayaan Koperasi, Usaha Mikro, Kecil dan Menengah (UMKM) melalui Lembaga Jeuangan Syariah (LKS) untuk Mengentaskan Kemiskinan dan Pengurangan Pengangguran. Jurnal Ekonomi Syariah.

Kanbur, Ravi; Kasekende, Louis; Aryeetey, Ernest; Devarajan, Shantayanan (2012). The Oxford companion to the economics of Africa. Oxford New York, New York: Oxford University Press.

Kaplinsky, R., et. al. (2000). "Spreading the Gains from Globalisation: What Can be Learned from Value Chain Analysis". IDS Working Paper No.110 Brighton. Insititute Development Studies.

Kreitner, Robert dan Angelo Kinicki. (2011). Perilaku Organisasi. Jakarta: Salemba Empat.

Newstrom. John W., Davis, Keith, (2007). Perilaku Dalam Organisasi. Edisi Ketujuh. Alih bahasa, Agus Dharma. Jakarta: Erlangga.

Pearce, J.A. \& Robinson, R.B,. (2005). Formulation, Implementation, and Control of Competitive Strategy. New York: Mc Graw Hill.

Salaam Gateway. (2020). Global Islamic Economic Report 2020.

Sugiyono. (2011). Metode Penelitian Kuantitatif, Kualitatif dan RED. Bandung: Alfabeta.

Trimo, STP. (2006). Evaluasi Penyuluhan Pertanian Permasalahan dan Upaya Pemecahannya di Kecamatan Banyudono Kabupaten Boyolali. Unpublished. 
al-Mizan, Vol. 5, No.1, hlm. 125-147, Februari 2021,

P.ISSN : 2085-6792, E.ISSN : 2656-7164

Walgito, Bimo. (2008). Psikologi Kelompok. Yogyakarta : Penerbit Andi. 